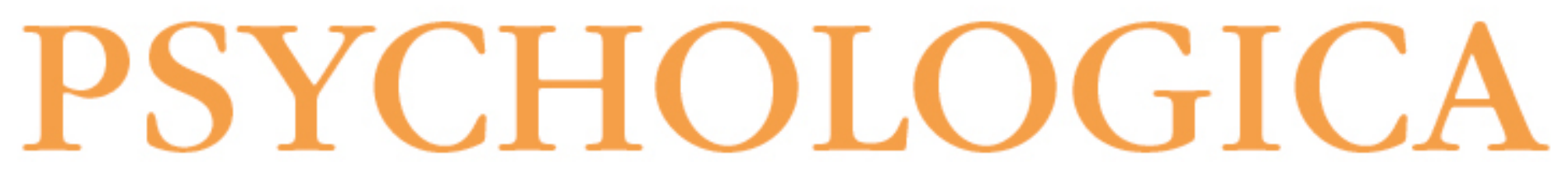

Relação da separação conjugal com as práticas parentais e o comportamento dos filhos

$\begin{array}{ll}\text { Autor(es): } & \text { Leme, Vanessa Barbosa Romera; Marturano, Edna Maria; Fontaine, } \\ & \text { Anne Marie }\end{array}$

Publicado por: Imprensa da Universidade de Coimbra

URL

persistente: URI:http://hdl.handle.net/10316.2/3436

DOI: $\quad$ DOI:http://dx.doi.org/10.14195/1647-8606_52-1_2

Accessed : $\quad$ 26-Apr-2023 05:08:53

A navegação consulta e descarregamento dos títulos inseridos nas Bibliotecas Digitais UC Digitalis, UC Pombalina e UC Impactum, pressupõem a aceitação plena e sem reservas dos Termos e Condições de Uso destas Bibliotecas Digitais, disponíveis em https://digitalis.uc.pt/pt-pt/termos.

Conforme exposto nos referidos Termos e Condições de Uso, o descarregamento de títulos de acesso restrito requer uma licença válida de autorização devendo o utilizador aceder ao(s) documento(s) a partir de um endereço de IP da instituição detentora da supramencionada licença.

Ao utilizador é apenas permitido o descarregamento para uso pessoal, pelo que o emprego do(s) título(s) descarregado(s) para outro fim, designadamente comercial, carece de autorização do respetivo autor ou editor da obra.

Na medida em que todas as obras da UC Digitalis se encontram protegidas pelo Código do Direito de Autor e Direitos Conexos e demais legislação aplicável, toda a cópia, parcial ou total, deste documento, nos casos em que é legalmente admitida, deverá conter ou fazer-se acompanhar por este aviso.

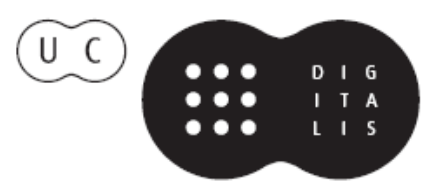




\section{NÚMERO 52}

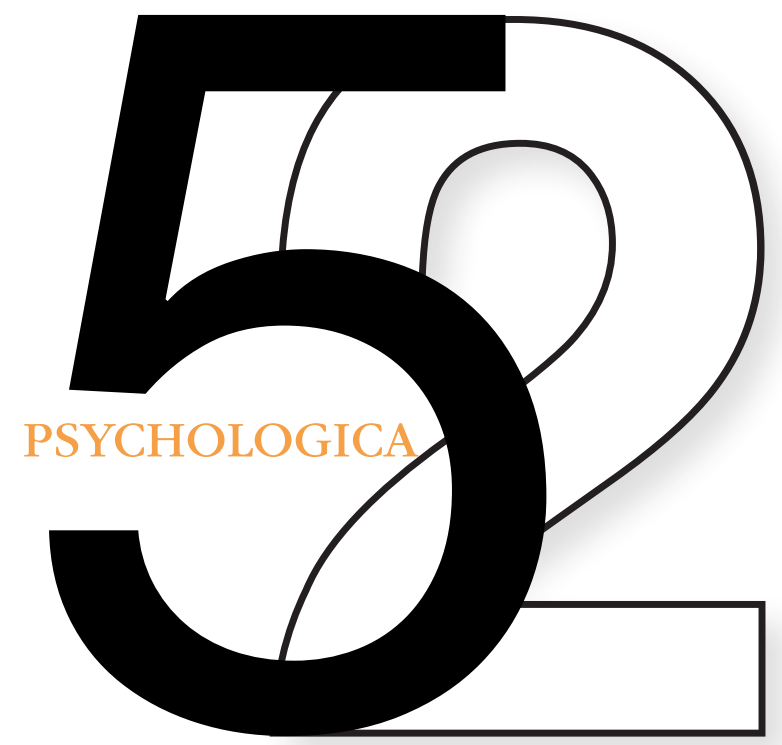

VOLUME I

IMPRENSA DA UNIVERSIDADE DE COIMBRA

FACULDADE DE PSICOLOGIA E DE CIÊNCIAS DA EDUCAÇÃO DA UNIVERSIDADE DE COIMBRA 


\title{
Relação da separação conjugal com as práticas parentais e o comportamento dos filhos
}

\begin{abstract}
Vanessa Barbosa Romera Leme², Edna Maria Marturano³ \& Anne Marie Fontaine ${ }^{4}$
Este estudo investiga as práticas educativas de mães de famílias nucleares e monoparentais e os comportamentos dos seus filhos na transição para o primeiro ano do ensino fundamental. Participam nesta pesquisa 33 mães de famílias nucleares, 33 mães que se tinham separado há menos de três anos e 33 mães que se tinham separado há mais de três anos. Os instrumentos utilizados são: Questionário Brasileiro de Avaliação do Nível Socioeconómico; Inventário de Práticas Parentais; Sistema de Avaliação de Habilidades Sociais. Os dois últimos instrumentos revelaram ter qualidades psicométricas adequadas. As ANOVAS indicam que as mães de famílias nucleares investem mais na educação dos filhos e manifestavam mais afecto às crianças do que as mães de famílias monoparentais recentes. Contudo, as mães das diferentes configurações familiares não se diferenciam nas práticas disciplinares. As crianças de famílias nucleares manifestam mais habilidades sociais e apresentam menos problemas de comportamento do que as crianças de famílias monoparentais. Na discussão salienta-se que as práticas parentais, o tempo da separação conjugal e o momento do desenvolvimento infantil são variáveis importantes que devem ser consideradas ao investigar-se o impacto das transições familiares sobre o desenvolvimento das crianças.
\end{abstract}

PALAVRAS-CHAVE: Separação conjugal; Práticas parentais; Comportamento infantil.

\section{Introdução}

A segunda metade do século passado foi marcada por muitas transformações sociais e económicas, tais como a redução dos empregos, o surgimento da pílula contraceptiva e a inserção da mulher no mercado de trabalho, que possibilita-

\footnotetext{
1 Apoio financeiro: Fundação de Amparo à Pesquisa do Estado de São Paulo - FAPESP

2 Aluna do programa de doutoramento da Faculdade de Filosofia, Ciências e Letras da Universidade de São Paulo de Ribeirão Preto - FFCLRP, Brasil - vanessaromera@gmail.com

3 Professora da Faculdade de Medicina da Universidade de São Paulo de Ribeirão Preto- FMRP, Brasil emmartur@fmrp.usp.br

4 Professora da Faculdade de Psicologia e de Ciências da Educação da Universidade do Porto - FPCEUP, Portugal. -fontaine@fpce.up.pt
} 
ram o aparecimento de novas configurações familiares. Face a esta realidade, verificaram-se mudanças que atingiram tanto a estrutura familiar como os papéis parentais. O modelo de família nuclear (pai, mãe e filhos) passou a coexistir com outros tipos de configurações familiares e o aumento exponencial das famílias monoparentais ${ }^{5}$ permitiu a construção de um novo cenário para o conceito de família (Wagner, 2002). Pelo que, desde meados dos anos 70 do século XX, pesquisadores de diversas áreas têm procurado investigar como a separação conjugal se repercute no desenvolvimento dos membros da família (Amato \& Cheadle, 2005; Hetherington \& Stanley-Hagan, 1999; Lansford, 2009; Strohschein, 2005).

\subsection{Separação conjugal e práticas parentais}

Alguns pesquisadores elegem um conjunto de variáveis a considerar na investigação da separação conjugal, cuja actuação, directa ou indirecta, sobre os membros da família, podendo levar ou não à disfunção. De entre estas variáveis, realça-se o conflito conjugal (Amato, 2000; Lansford, 2009), a presença/ausência do cônjuge não detentor da guarda dos filhos (Hetherington \& Stanley-Hagan, 1999; Kelly \& Emery, 2003), o tempo de separação conjugal (Amato, 2000; Hetherington \& Stanley-Hagan, 1999; Lansford, 2009), os factores económicos (Amato, 2005; Kelly \& Emery, 2003), a idade da criança/adolescente na época da separação (Amato, 2000; Lansford, 2009), o sexo da criança/adolescente (Amato, 2000; Leon, 2003), a rede de apoio social (Hetherington \& Stanley-Hagan, 1999; Kelly \& Emery, 2003) e as práticas parentais (Amato 2000, Hetherington \& Stanley-Hagan, 1999, Martinez \& Forgatch, 2002; Wolchick e et al., 2000). O presente estudo seleccionou as práticas parentais e o tempo de separação conjugal como variáveis importantes no ajustamento familiar durante este tipo de transição.

Alguns estudos têm encontrado diferenças entre as práticas parentais de famílias que passaram ou não pela separação conjugal (Costa, Cia \& Barham, 2007; Hetherington, 1993). Para Alvarenga e Piccinini (2001), as práticas parentais podem ser definidas como estratégias utilizadas pelos pais para promover a socialização dos filhos. Vários estudos têm sinalizado que as práticas parentais ${ }^{6}$ tidas como

\footnotetext{
5 Encontramos na literatura um conjunto de denominações para os diferentes tipos de famílias: as famílias compostas por pai, mãe e filhos da primeira união conjugal são denominadas, por exemplo, de nucleares ou tradicionais; as famílias remanescentes após a separação conjugal são denominadas, por exemplo, de mononucleares ou monoparentais. Neste estudo serão adotadas as seguintes nomenclaturas: família nuclear e família monoparental.

$6 \mathrm{Na}$ literatura encontram-se diversas denominações para as estratégias e técnicas que os pais utilizam para a promoção do desenvolvimento psicossocial dos filhos: práticas indutivas e coercitivas (Hoffman,
} 
coercitivas (tais como uso de agressão verbal e/ou física, ameaças e retirada de privilégios), permissivas (por exemplo, quando os pais não estabelecem limites aos filhos) e inconsistentes (tais como quando os pais ora estabelecem limites, ora não, ora expressam afeto, ora não) estão associadas com dificuldades comportamentais, emocionais e com baixo rendimento académico em crianças (Baumrind, 1971; Gomide, 2003; Dishion \& McMahon, 1998; Hoffman, 1979; Kilgore, Snyder \& Lentz, 2000). Por outro lado, as práticas parentais caracterizadas pela expressão de afecto, consistência nas práticas disciplinares, envolvimento parental com as actividades escolares e de lazer dos filhos e monitorização das actividades da criança estão relacionadas, muitas vezes, com um repertório elaborado de habilidades sociais, com um relacionamento satisfatório com pares e familiares e com um bom desempenho académico das crianças (Baumrind, 1971; Dishion \& McMahon, 1998; Hoffman, 1979; Kilgore et al., 2000).

Segundo alguns autores (Fortgatch \& DeGarmo, 1999; Martinez \& Forgatch, 2002; Hetherington, 1993; Pruett e cols., 2003; Wolchick et al., 2000), determinadas circunstâncias que ocorrem após a separação conjugal podem contribuir para que pais e mães recorram a práticas parentais menos favoráveis, coercitivas e/ ou permissivas. Forgatch e DeGarmo (1999), nomeadamente, afirmam que após a separação conjugal, o cônjuge detentor da guarda, na maior parte das vezes, a mãe, teria dificuldades em estabelecer limites aos filhos e trabalhar ao mesmo tempo, ficando muitas vezes sob efeito do estresse e fazendo uso de ameaças de agressões e/ou agressões verbais e físicas. Martinez \& Fortach (2002) encontraram práticas parentais das mães menos positivas nos dois primeiros anos após a separação conjugal, pois há diminuição na comunicação e no controle dos comportamentos dos filhos, bem como nas habilidades de resolução de problemas maternos. Além disso, os autores encontraram associações positivas entre os problemas de comportamento e baixo rendimento acadêmico das crianças e as práticas coercitivas das mães.

Outros autores salientam que, após a ruptura conjugal, as mães também podem ficar deprimidas, e assim, expressam menos afecto e atenção aos filhos e apresentam menos consistência nas suas práticas educativas (Pruett et al., 2003; Wolchick et al., 2000). A maioria dos pesquisadores (Amato, 2000, 2005; Heterington, 1993; Lansford, 2009) tem também sinalizado que as crianças que passam por estas transições familiares podem apresentar, a curto, médio e longo prazo, mais problemas comportamentais, dificuldades académicas e menos bem-estar psicológico quando comparadas com as crianças provenientes de famílias nucleares. Entretanto, apenas uma minoria dessas crianças apresenta dificuldades sócio-emocionais e

1979), práticas educativas positivas e negativas (Gomide, 2003) e os estilos parentais autoritário, autoritativo e permissivo (Baumrind, 1971). 
comportamentais (Amato, 2000; Leon, 2003). Estas não ocorrem quando a criança convive com uma figura parental que apresenta práticas educativas positivas tais como oferta de atenção e afecto, monitorização das actividades escolares e de lazer da criança e que negoceia de forma adequada com o ex-cônjuge a guarda dos filhos (Heterington \& Stanley-Hagan, 1999).

Parece haver pouco consenso entre os investigadores quanto à extensão e severidade das dificuldades apresentadas pelas crianças em resposta à separação conjugal (Hetherington, Bridges \& Glendessa, 1998). No entanto, ainda que não haja um consenso a respeito dos efeitos da separação conjugal sobre o relacionamento entre pais e filhos e sobre o desenvolvimento infantil, o mesmo não acontece quanto ao reconhecimento das transições familiares como fonte de estresse para todos os envolvidos.

\subsection{O tempo de separação conjugal}

As famílias necessitam de tempo para que a estabilidade e previsibilidade se restabeleçam no ambiente familiar (Amato, 2000; Hetherington \& Stanley-Hagan, 1999), tempo que varia de dois a três anos (Amato \& Keith, 1991; Clarke-Stewart \& et al., 2000; Hetherington, 1993). Diversos estudos salientam que os efeitos negativos observados nas relações entre pais e filhos e no desenvolvimento infantil são temporários e mais acentuados nos primeiros anos após a separação conjugal (Amato, 2000; Heterington \& Stanley-Hagan, 1999, Strohschein, 2005).

Wood, Repetti e Roesch (2004) realizaram um estudo longitudinal que procurou investigar se os problemas de comportamento internalizantes e externalizantes infantis eram mais intensos em famílias monoparentais, cujas mães estavam separadas há mais de três anos, em relação às famílias nucleares. Na percepção das mães, as crianças de famílias monoparentais apresentavam mais problemas de comportamento internalizantes e externalizantes, do que as crianças de famílias nucleares. Contudo, as diferenças foram diminuindo ao longo dos anos, indicando que as crianças de famílias separadas há menos tempo são mais susceptíveis de apresentar dificuldades comportamentais. Em outro estudo longitudinal, Lansford et al. (2006) encontraram resultados semelhantes aos de Wood et al. (2004) ao procurar examinar se a ocorrência e o tempo da separação estavam relacionados com a intensidade dos problemas comportamentais e académicos de crianças que foram acompanhadas da pré-escola até o último ano do ensino fundamental. Os autores também encontraram que as crianças de famílias monoparentais apresentavam mais problemas de comportamento externalizantes e internalizantes, 
principalmente nos primeiros anos após a separação conjugal, em comparação com as crianças de famílias nucleares.

Os estudos mencionados indicam que as crianças de famílias monoparentais são mais vulneráveis a dificuldades comportamentais, principalmente nos primeiros anos após a separação conjugal, em comparação com as crianças de famílias nucleares. Todavia, algumas pesquisas evidenciam também que, em certos casos, os efeitos negativos da separação conjugal sobre as relações entre pais e filhos e sobre o desenvolvimento infantil não diminuem com o tempo (Amato \& Cheadler, 2005; Amato \& Keith, 1991; Hetherington, 1993). Verifica-se, pois, que o tempo de separação conjugal parece ser uma variável importante na análise do desenvolvimento infantil em famílias monoparentais. Além disso, ao lado dos problemas comportamentais, que têm recebido maior ênfase na pesquisa, seria interessante investigar as mudanças nas habilidades sociais, também consideradas por alguns autores como factores de protecção durante as transições familiares (Amato, 2000; Hetherington \& Stanley-Hagan, 1999).

\subsection{Separação conjugal e transição para o ensino fundamental}

Alguns estudos evidenciam que a separação conjugal pode ser mais prejudicial para os filhos quando ocorre nos anos pré-escolares e nos primeiros anos de escolaridade (Clarke-Stewrat et al., 2000; Leon, 2003; Pruett et al., 2003; Ramires, 2004; Wood et al., 2004). Crianças desta faixa etária são consideradas mais vulneráveis face ao estresse da separação conjugal porque seriam menos capazes de lidar cognitivamente com a situação que vivenciam (Wood et al., 2004). Além disso, devem gerir diversas transições simultaneamente. Por um lado, têm de lidar com os desafios das habilidades académicas a adquirir e com as regras de convívio social do ambiente escolar (Pruett et al., 2003). Por outro lado, estas crianças menores têm ao mesmo tempo de conviver com mudanças nos papéis e funções parentais decorrentes da separação conjugal (Page \& Bretherton, 2003). Contudo, poucos estudos avaliam os efeitos do divórcio sobre crianças nesta faixa etária (Clarke-Stewrat et al., 2000; Leon, 2003). Ramires (2004), ao entrevistar crianças e pré-adolescentes para saber como essas vivenciavam a separação conjugal e as novas uniões dos pais, verificou que as crianças que tinham passado pela separação dos pais nos anos pré-escolares apresentavam mais sentimentos de ansiedade, medo de abandono, conflitos de lealdade e mais problemas comportamentais e académicos, em comparação com as crianças que tinham vivenciado as transições familiares mais tardiamente. 
Crianças de famílias que se encontram em fase de separação podem ter maior dificuldade para lidar com outros desafios do desenvolvimento como, por exemplo, as transições escolares. A entrada da criança no primeiro ano de escolaridade pode ser vista como um desses períodos em que a acumulação de exigências novas pode deixar algumas crianças mais vulneráveis à instabilidade familiar. Pesquisas que investigam factores de protecção para a entrada no ensino fundamental consideraram precisamente que o apoio parental (Ackerman et al., 1999), a estabilidade no ambiente familiar (Johnson, Cowan \& Cowan, 1999) e as práticas parentais positivas (Trivellato-Ferreira \& Marturano, 2008) facilitam o ajustamento da criança no ensino fundamental, bem como previnem problemas de comportamento e de aprendizagem. Ora, verifica-se que o ambiente familiar, nos primeiros anos após a separação conjugal, tende a ser mais instável e imprevisível, prejudicando as relações entre pais e filhos e o desenvolvimento infantil (Amato, 2000; Hetherington \& Stanley-Hagan, 1999). Frente a estes dados, é possivel que a instabilidade e a imprevisibilidade verificadas no ambiente das famílias que passam pela separação conjugal sejam condições que potencializam o uso de práticas parentais coercitivas, permissivas ou inconsistentes, dificultam o apoio dos pais aos filhos em relação às exigências encontradas na transição para o primeiro ano e, desta forma, contribuem para o surgimento de dificuldades sociais e comportamentais.

\section{Objectivos e hipóteses}

É objectivo deste estudo investigar as práticas educativas de mães de famílias nucleares e monoparentais recentes (separadas há menos de três anos) e remotas (separadas há mais de três anos) e os comportamentos dos seus filhos (habilidades sociais e problemas de comportamento) que passam pela transição para o ensino fundamental.

Tem-se por hipótese que as mães de famílias nucleares e monoparentais remotas apresentarão mais práticas educativas positivas tais como exprimir sentimentos positivos, oferecer atenção, participar de actividades de lazer com os filhos, monitorizar as actividades escolares, e menos práticas coercitivas, permissivas ou inconsistentes do que as mães de famílias monoparentais recentes. Paralelamente, espera-se que, segundo os relatos das mães, as crianças de famílias nucleares e monoparentais remotas apresentem mais habilidades sociais e menos problemas de comportamento em comparação com as crianças de famílias monoparentais recentes. 
As hipóteses do estudo apoiam-se em pesquisas que sinalizam que os efeitos das transições familiares são passageiros, ou seja, com o passar do tempo (em torno de três anos após a separação conjugal), as famílias ajustam-se às novas configurações e as crianças deixam de apresentar as dificuldades emocionais e/ou comportamentais evidenciadas logo após a separação (Amato, 2000; Heterington \& Stanley-Hagan, 1999).

\section{Método}

\subsection{Participantes}

A amostra é composta por 99 mães (33 mães de famílias nucleares, 33 mães de famílias monoparentais recentes e 33 mães de famílias monoparentais remotas) de crianças a frequentar o primeiro ano do ensino fundamental. Os alunos estavam matriculados em cinco escolas da rede municipal de uma cidade do interior do Estado de São Paulo com 558.136 habitantes.

Para participar do estudo, as mães deveriam corresponder a alguns critérios de inclusão. Em todos os tipos de configuração familiar, as crianças deveriam residir com a mãe. Critérios específicos de inclusão nos diferentes grupos foram estabelecidos de acordo com o que se entende, neste trabalho, por famílias nucleares e monoparentais: 1) Famílias nucleares: quando a mãe biológica da criança coabitava com o pai biológico da criança desde o seu nascimento; 2) Famílias monoparentais: quando a mãe biológica da criança não coabitava com o pai biológico da criança ou com outro parceiro; a mãe deveria ter coabitado com o ex-cônjuge durante no mínimo um ano (a contar do nascimento da criança). Para a família ser considerada como monoparental recente, a mãe deveria estar separada há pelo menos seis meses e há menos de três anos; para ser considerada como família monoparental remota, a mãe deveria estar separada há mais de três anos.

\subsection{Informações sóciodemográficas}

As análises estatísticas indicaram que as famílias são homogéneas em relação a diversas variáveis: escolaridade das mães (nuclear: média 7,91- d.p.=2,56, monoparental recente: média 8,85 - d.p.=2,43, monoparental remota: média 8,70 - d.p.=2,89; $F=1,52, p=0,224$ ); rendimento familiar (nuclear: $R \$ 1271,21$ - d.p.= R\$ 586,43, monoparental recente: $R \$ 1030,30$ - d. $p .=R \$ 444,04$, monoparental remota: $R \$ 1071,97$ - d. $p,=R \$ 525,77 ; F=2,00, p=0,140$ ); género das crianças (44 meninas e 55 meninos; $\chi^{2}=1,22, p=0,269$ ). A idade média das mães que participaram da 
pesquisa foi de 32,6 anos (d.p.=5,76). As mães do estudo encontravam-se entre a classe média-baixa e média (rendimento familiar entre $\mathrm{R} \$ 861,00$ e $\mathrm{R} \$ 1.318,00$ ). Essas classes correspondem a $44 \%$ da distribuição da população do Estado de São Paulo, Brasil (ABEP, 2008).

\subsection{Instrumentos}

Práticas educativas parentais: Utilizou-se o Inventário de Práticas Parentais (IPP), destinado a pais e mães com filhos em idade escolar. Trata-se de um instrumento baseado na teoria sócio-cognitiva e sistémica, construído por Benetti e Balbinotti (2003). O inventário é composto por 29 itens que apresentam actividades ou comportamentos relativamente aos quais as mães devem estimar o grau de ocorrência, numa escala de tipo Likert em cinco pontos: 5 = muito frequentemente; 4 = frequentemente; 3 = algumas vezes, 2 = raramente, 1 = nunca. $O$ IPP contempla cinco dimensões referentes às práticas parentais: Social ( 6 itens, participação dos pais em actividades de lazer com os filhos, exemplo: "participa de jogos e actividades com o filho"); Educação (6 itens, habilidades dos pais em supervisionar e monitorizar as experiências dos filhos na escola e em perceber as dificuldades da criança face a situações de conflito em algum aspecto social, exemplo: "Eu ensino meu filho as matérias que ele não entende na escola"); Disciplina (5 itens, comportamentos dos pais quando estabelecem limites aos filhos, baseados em práticas coercitivas e/ou permissivas e/ou inconsistentes, exemplo: "Eu grito com meu filho quando ele faz alguma coisa errada"); Afecto (8 itens, habilidades dos pais de expressar afecto aos filhos, exemplo: "Eu abraço e beijo meu filho"); Responsabilidade (4 itens, comportamentos dos pais que expressam preocupação com o bem estar da criança, exemplo: "Eu posso estar ocupada, mas meu filho sabe aonde me encontrar se precisar de algo").

Grybowski (2007), ao avaliar 234 pais e mães, utilizando a versão do IPP com 29 itens, encontrou um bom índice de consistência interna global através do coeficiente alfa de Cronbach = 0,90. Embora no estudo de Benetti e Balbinotti (2003) os valores da consistência interna possam ser considerados baixos em alguns factores (Afecto alfa =0,76; Educação alfa $=0,82$, Disciplina alfa $=0,55$; Social alfa $=0,58)$, tais resultados podem ser devidos ao facto de ter utilizado uma versão mais curta do instrumento (16 itens).

A estrutura multidimensional do Inventário de Práticas Parentais (IPP) foi confirmada neste estudo a partir de uma análise factorial confirmatória para cada dimensão, utilizando o programa AMOS 16.o. Para isso, foi seleccionada uma amostra de 160 mães de crianças que frequentavam a primeira série do ensino 
fundamental. Os índices de ajustamento obtidos com a análise factorial confirmatória indicaram que o modelo teórico do IPP se ajustou à amostra do estudo. Foram em seguida avaliados os índices de consistência interna (coeficiente alfa de Cronbach) das diversas dimensões do instrumento. Para aumentar o valor de alfa da dimensão Responsabilidade foi retirado o item 28 ("Eu converso com meu esposo (a)/companheiro (a) sobre o futuro de meu filho (a)").

Comportamentos infantis (habilidades sociais e problemas de comportamento): Utilizou-se o Sistema de Avaliação de Habilidades Sociais (Social Skills Rating System ou SSRS-BR, versão para pais) para avaliar o repertório de habilidades sociais e problemas de comportamento infantis, por meio de questionários dirigidos aos pais. Este instrumento foi desenvolvido e validado nos Estados Unidos por Gresham e Elliott (1990). No Brasil, foi traduzido e validado para crianças do $1^{\circ}$ ao $4^{\circ}$ ano de escolaridade, por Bandeira et al. (2009). A versão para pais (SSRSBR) possui 38 itens para avaliar a frequência e a importância das habilidades sociais e 17 itens para avaliar a frequência de comportamentos problemáticos. As alternativas de respostas estão dispostas numa escala de tipo Likert (o = nunca, 1 = algumas vezes e 2 = muito frequente). A escala de habilidades sociais é composta por 6 dimensões: Cooperação (10 itens, comportamentos de colaboração da criança, sem ter sido solicitado, exemplo: "Faz as tarefas domésticas que são estabelecidas como suas sem precisar de ser lembrado"); Amabilidade (8 itens, comportamentos da criança que geram a estima dos outros, exemplo: "É querido pelos outros"); Iniciativa/Desenvoltura Social (8 itens, comportamentos de iniciação e manutenção das interacções sociais, exemplo: "Faz amigos com facilidade"); Asserção (8 itens, comportamentos que expressam confiança em lidar com estranhos e situações novas, exemplo: "Atende o telefone de uma forma adequada"); Autocontrole/Civilidade (6 itens, comportamentos que demonstram domínio sobre as próprias emoções, através de reacções abertas, exemplo: "Recusa civilizadamente pedidos abusivo dos outros"); Autocontrole Passivo (4 itens, comportamentos que indicam domínio sobre as próprias emoções, por

\footnotetext{
7 Social: $C M I N / D F=0,450 ; G F I=0,993 ; A G F I=0,980 ;$ RMSEA = 0,000 - Educação: CMIN/DF = 1,891; GFI = 0,969; $\mathrm{AGFI}=0,919 ; \mathrm{RMSEA}=0,072$ - Disciplina: $\mathrm{CMIN} / \mathrm{DF}=1,182 ; \mathrm{GFI}=0,989 ; \mathrm{AGFI}=957 ; \mathrm{RMSEA}=$ 0,034 - Afeto: $C M I N / D F=1,670 ; \mathrm{GFI}=961 ; \mathrm{AGFI}=0,912 ; \mathrm{RMSEA}=0,065$ - Responsabilidade: CMIN/DF $=1,370 ; \mathrm{GFI}=0,992 ; \mathrm{AGFI}=0,958 ;$ RMSEA $=0,048$.
} 
meio de reações encobertas, exemplo: "Controla sua irritação quando discute com os outros"). A escala de comportamentos problemáticos está dividida em 3 dimensões: Hiperatividade ( 6 itens, comportamentos que envolvem movimento excessivo, inquietação, exemplo: "É irrequieto e mexe-se excessivamente");

Externalizantes ( 7 itens, comportamentos que envolvem agressão física ou verbal de outras pessoas, exemplo: "Briga com os outros"); Internalizantes (4 itens, comportamentos que expressam distanciamento dos demais e sentimentos de ansiedade, tristeza e baixa auto-estima, exemplo: “Parece solitário"). Na validação do SSRS-BR, os autores administraram o instrumento, quer a pais (312), quer a professores (86) para avaliar crianças (416), do $1^{\circ}$ ao $4^{\circ}$ ano de escolaridade de escolas públicas e particulares, em cinco cidades de quatro estados brasileiros. Os resultados mostraram uma estrutura de componentes que explicaram de $40 \%$ a $62 \%$ da variância dos dados. Os índices de consistência interna das escalas globais e das dimensões foram satisfatórios: escala de habilidades sociais alfa $=0,86$ (Cooperação alfa $=0,79$, Amabilidade lf $a=0,70$, Iniciativa/Desenvoltura Social alfa $=0,71$, Asserção alfa =0,70, Autocontrole/Civilidade alfa $=0,59$, Autocontrole Passivo alfa = 0,65); e escala de avaliação dos comportamentos problemáticos alf $a=0,83$ (Hiperatividade alf $a=0,75$, Externalizantes alf $a=0,72$, Internalizantes alfa $=0,60$ ). A análise da estabilidade temporal indicou correlações teste-reteste razoáveis e significativas para os escores globais das escalas de habilidades sociais $(r=0,69)$ e de comportamentos problemáticos $(r=0,75)$.

Para este estudo, procurou-se confirmar as qualidades psicométricas, recorrendo à análise factorial confirmatória para cada dimensão, para verificar em que medida o modelo teórico proposto no SSRS-BR se adequava aos dados colectados, e procedeu-se à análise da consistência interna das diversas escalas do instrumento. O instrumento foi testado junto de uma amostra de 160 mães de crianças que frequentavam o primeiro ano do ensino fundamental, de escolas municipais. Os indices ${ }^{8}$ de ajustamento obtidos com a análise factorial confirmatória sugeriram que o modelo teórico proposto pelo SSRS-BR se ajusta aos dados da amostra. Contudo a obtenção destes índices na análise da dimensão Autocontrole Passivo, exigiu a retirada do item 17 ("aceita críticas").

Foram encontrados, neste estudo, índices de consistência interna satisfatórios na maioria das dimensões do SSRS-BR, seja na escala de habilidades sociais (Coope-

\footnotetext{
8 Cooperação: $C M I N / D F=1,444 ; G F I=0,947 ; A G F I=0,906 ;$ RMSEA = 0,053- Amabilidade: CMIN/DF = 1,447; GFI = 0,960; AGFI = 0,920; RMSEA = 0,053-Iniciativa/Desenvoltura Social: CMIN/DF = 1,350; GFI = 0,966; $\mathrm{AGFI}=0,924 ;$ RMSEA = 0,047 - Asserção: CMIN/DF = 1,417; GFI = 0,960; AGFI = 0,924; RMSEA = 0,051 - Autocontrole/Civilidade: CMIN/DF = 1,685; GFI = 973; $\mathrm{AGFI}=0,928 ; \mathrm{RMSEA}=0,066$ - Autocontrole Passivo: CMIN/DF = 2,644; GFI = 0,985; $\mathrm{AGFI}=0,976$; RMSEA = 0,087 - Hiperatividade: CMIN/DF = 1,355; GFI = 0,979; $\mathrm{AGFI}=0,944 ; \mathrm{RMSEA}=0,047$ - Externalizante: $\mathrm{CMIN} / \mathrm{DF}=1,113 ; \mathrm{GFI}=0,973 ; \mathrm{AGFI}$ $=0,946 ;$ RMSEA $=0,027$.
} 
ração alfa $=0,85$, Amabilidade alfa $=0,73$; Iniciativa/Desenvoltura Social alfa $=$ 0,76 , Asserção alfa =0,61, Autocontrole/Civilidade $a l f a=0,73$, Autocontrole Passivo alfa $=0,90$ ), seja na de comportamentos problemáticos (Hiperatividade $a l f a=$ 0,78 , Externalizantes alfa = 0,79). A exceção foi o componente Internalizantes da escala de comportamentos problemáticos $(a l f a=0,37)$, pelo que esta dimensão não foi utilizada nas análises posteriores. No geral, as análises confirmaram as boas qualidades psicométricas do SSRS-BR para a amostra avaliada neste estudo.

Caracteristicas sociais e demográficas: Foi utilizado o Questionário Critério Brasil (www.ibope.com.br) que permite avaliar o nível socioeconómico e é composto por onze itens: nove que investigam o número de bens de consumo duráveis da família, um item que investiga o grau de instrução do chefe da família e um item que avalia o número de empregadas domésticas na casa. Esta medida estratifica a sociedade brasileira em cinco classes: $A$ (subdividida em A1 e A2), B (subdividida em B1 e B2), C (subdividida em C1 e C2), D e E.

\subsection{Procedimento de colecta e análise de dados}

Para a selecção da amostra, após a assinatura do Termo de Consentimento Livre e Esclarecido (TCLE), 22 professoras de cinco escolas municipais de Ensino Fundamental foram solicitadas a mandarem, através do caderno de recado dos alunos, um comunicado a todas as mães. Essa informação explicava brevemente a pesquisa e convidava as mães a participarem no estudo, solicitando para isso um meio de contacto (por exemplo, telefone fixo e/ou telemóvel) e perguntando o seu estado civil (casada, separada ou recasada). Em posse das respostas, a pesquisadora entrava em contacto com as mães, por telefone, para verificar o interesse em participar do estudo e conferir os critérios de inclusão. Em seguida, havendo interesse das mães, a pesquisadora marcava um encontro para a assinatura do TCLE e para a aplicação dos instrumentos.

A colecta de dados com as mães foi realizada individualmente nas suas residências ou locais de trabalho. Imediatamente antes da aplicação dos instrumentos, a pesquisadora retomava os objectivos da pesquisa, entregava à mãe uma via do TCLE e lia em voz alta o conteúdo desse documento noutro exemplar. Mediante a assinatura do TCLE, a pesquisadora aplicava os instrumentos com as mães na seguinte ordem: 1) Questionário sobre Caracterização Familiar; 2) Inventário de Práticas Parentais; 3) Sistema de Avaliação de Habilidades Sociais; 4) Questionário Critério Brasil. Na aplicação desses instrumentos, a pesquisadora lia cada pergunta em voz alta e anotava as respostas das mães, para ultrapassar qualquer dificuldade que as mães tivessem em relação à leitura do instrumento. 
$\mathrm{Na}$ análise dos dados, a normalidade da distribuição das variáveis foi previamente testada (Kolmogorov-Smirnov). Para as variáveis com distribuição normal, os grupos foram comparados por meio de ANOVA, com o teste post hoc de Bonferroni, em caso de homogeneidade das variáveis, ou o teste Dunnett's T3, em caso de heterogeneidade. Para variáveis com distribuição não normal, as comparações foram feitas com o teste de Kruskal-Wallis, utilizando-se o teste Post Hoc LSD de Fisher, de acordo com a recomendação de Maroco (2007).

\section{Resultados}

A Tabela 1 apresenta os resultados a respeito das Práticas Educativas Parentais nas dimensões Educação, Disciplina, Afecto e Responsabilidade para as famílias nucleares, monoparentais recentes e monoparentais remotas.

Tabela 1. Práticas Parentais: média, desvio-padrão das variáveis para as famílias nucleares e monoparentais recentes e remotas.

\begin{tabular}{lcccc}
\hline \multicolumn{4}{c}{ Famílias/Categorias } \\
\hline Variável & $\begin{array}{c}\text { Nuclear } \\
(\mathrm{n}=33)\end{array}$ & $\begin{array}{c}\text { Monoparental } \\
\text { recente } \\
(\mathrm{n}=33)\end{array}$ & $\begin{array}{c}\text { Monoparental } \\
\text { remota } \\
(\mathrm{n}=33)\end{array}$ & $\mathrm{F} / \mathrm{\chi}^{2}$ \\
\cline { 2 - 4 } & Média (dp) & Média (dp) & Média (dp) & \\
\hline Práticas Parentais & & & & \\
Educação & $26,64^{\mathrm{a}}(2,9)$ & $22,21^{\mathrm{b}}(4,25)$ & $23,58^{\mathrm{b}}(4,25)$ & $18,97^{2^{*}}$ \\
Disciplina & $12,64^{\mathrm{a}}(4,50)$ & $14,64^{\mathrm{a}}(4,56)$ & $13,91^{\mathrm{a}}(4,37)$ & $1,29^{1}$ \\
Afeto & $38,42^{\mathrm{a}}(3,48)$ & $35,79^{\mathrm{b}}(4,69)$ & $36,79^{\mathrm{ab}}(3,14)$ & $11,93^{2^{*}}$ \\
Responsabilidade & $14,94^{\mathrm{a}}(0,34)$ & $14,79^{\mathrm{ab}}(0,48)$ & $14,61^{\mathrm{b}}(0,74)$ & $7,03^{2^{*}}$ \\
\hline
\end{tabular}

*p ffi o,05

'Variável normal

${ }^{2}$ Variável não normal

${ }^{\mathrm{ab}}$ As médias com os mesmos índices não são significativamente diferentes no teste Post Hoc

De acordo com os resultados da Tabela 1, as mães de famílias nucleares declaram (i) investir na educação dos filhos com mais frequência de que as mães de famílias monoparentais recentes e remotas, (ii) expressar mais afecto do que as mães de famílias monoparentais recentes e (iii) demonstrar mais preocupação com o bemestar dos filhos do que as mães de famílias monoparentais remotas. Por sua vez, as mães de famílias monoparentais recentes e remotas não se diferenciam quanto a essas práticas parentais. E as mães de famílias nucleares não se diferenciam das mães de famílias monoparentais recentes e remotas, quanto à demonstração de responsabilidade e expressão de afeto, respectivamente. Constata-se que os diferentes tipos de configuração familiar não exercem nenhum efeito sobre a 
dimensão Disciplina, que inclui as práticas disciplinares consideradas negativas, ou seja as práticas coercitivas, permissivas ou inconsistentes.

A Tabela 2 apresenta os resultados relativos às habilidades sociais e aos problemas de comportamento das crianças, do ponto de vista das mães das famílias nucleares e monoparentais recentes e remotas.

Tabela 2. Habilidades Sociais e Problemas de Comportamento das crianças: média, desviopadrão das variáveis para as famílias nucleares e monoparentais recentes e remotas.

\begin{tabular}{|c|c|c|c|c|}
\hline \multicolumn{5}{|c|}{ Famílias/Categorias } \\
\hline \multirow[t]{2}{*}{ Variável } & $\begin{array}{c}\text { Nuclear } \\
(n=33)\end{array}$ & $\begin{array}{l}\text { Monoparental } \\
\text { recente } \\
(n=33)\end{array}$ & $\begin{array}{c}\text { Monoparental } \\
\text { remota } \\
(\mathrm{n}=33)\end{array}$ & \multirow[t]{2}{*}{$F / X^{2}$} \\
\hline & Média (dp) & Média (dp) & Média (dp) & \\
\hline \multicolumn{5}{|l|}{ Habilidades Sociais } \\
\hline Cooperação & $12,30^{\text {a }}(4,66)$ & $9,33^{b}(4,97)$ & $10,15^{\mathrm{ab}}(5,02)$ & $3,24^{1 *}$ \\
\hline Amabilidade & $13,06^{\mathrm{a}}(2,20)$ & $10,61^{b}(3,31)$ & $10,76^{\mathrm{ab}}(3,12)$ & $11,96^{2 *}$ \\
\hline $\begin{array}{l}\text { Iniciativa/ } \\
\text { Desenvoltura social }\end{array}$ & $9,85^{a}(3,24)$ & $9,33^{a} \quad(3,73)$ & $9,33^{\mathrm{a}}(3,56)$ & $0,56^{2}$ \\
\hline Asserção & $11,06^{a}(2,63)$ & $10,36^{\mathrm{a}}(2,77)$ & $10,39^{a}(6,96)$ & $0,77^{1}$ \\
\hline $\begin{array}{l}\text { Autocontrole } \\
\text { Civilidade }\end{array}$ & $7,61^{a}(1,90)$ & $5,09^{b}(2,40)$ & $5,42^{b}(2,91)$ & $10,32^{1 *}$ \\
\hline $\begin{array}{l}\text { Autocontrole } \\
\text { Passivo }\end{array}$ & $5,27^{\mathrm{a}}(2,55)$ & $3,45^{b}(2,00)$ & $3,91^{b}(2,33)$ & $11,86^{2 *}$ \\
\hline \multicolumn{5}{|l|}{$\begin{array}{l}\text { Problemas de Com- } \\
\text { portamento }\end{array}$} \\
\hline Hiperatividade & $2,70^{\mathrm{a}}(2,32)$ & $5,12^{b}(2,89)$ & $4,55^{b}(2,79)$ & $7,35^{1 *}$ \\
\hline Externalizante & $3,09^{\mathrm{a}}(2,69)$ & $5,91^{\mathrm{b}}(3,30)$ & $4,36^{\mathrm{a}}(3,37)$ & $11,97^{2 *}$ \\
\hline
\end{tabular}

${ }^{*}$ p ffi o,05

'Variável normal

${ }^{2}$ Variável não normal

${ }^{\mathrm{ab}}$ As médias com os mesmos índices não são significativamente diferentes no teste Post Hoc

Constata-se pela Tabela 2, que as mães de famílias nucleares relatam que seus filhos apresentavam com mais frequência, em comparação com as crianças de famílias monoparentais recentes e remotas, habilidades sociais de Autocontrole quer em termos de Civilidade, quer Passivo. Além disso, as crianças de famílias nucleares são percebidas pelas mães como apresentando mais habilidades de Cooperação e de Amabilidade, em comparação com as crianças de famílias monoparentais recentes, mas não remotas. Para qualquer uma das habilidades sociais investigadas, as crianças de famílias monoparentais recentes e remotas não se diferenciam.

No que diz respeito aos problemas de comportamento, as mães de famílias monoparentais recentes e remotas dizem que seus filhos são mais hiperactivos do que as crianças de famílias nucleares. As crianças de famílias monoparentais 
recentes e remotas não se diferenciam para os problemas de hiperactividade. Os problemas de comportamento externalizantes foram mais frequentes nas crianças de famílias monoparentais recentes do que nas crianças de famílias nucleares ou monoparentais remotas. As crianças de famílias nucleares e as de famílias monoparentais remotas não se diferenciam para os problemas de comportamento externalizantes.

\section{Discussão}

Segundo a literatura (Amato 2000, Hetherington \& Stanley-Hagan, 1999, Woods et al., 2004), as práticas educativas parentais, o tempo da separação conjugal e o momento do desenvolvimento infantil são variáveis que devem ser consideradas ao analisar-se o ajustamento das famílias que passam por transições. Algumas pesquisas têm encontrado que os resultados negativos observados nos comportamentos das crianças cujos pais se separaram podem ser decorrentes da utilização mais recorrente de práticas educativas parentais tais como ameaças de agressões, agressões verbais e/ou físicas, inconsistência nas práticas disciplinares, permissividade, falta de monitoria, afecto e negligência (Amato, 2005; Hetherington \& Stanley-Hagan, 1999; Martinez \& Forgatch, 2002; Pruett et al., 2003). Tais práticas aumentam a probabilidade de as crianças apresentarem dificuldades comportamentais, emocionais e acadêmicas (Dishion \& McMahon, 1998; Hildyard \& Wolfe, 2002; Kilgore et al., 2000). Contudo, estas perturbações são temporárias e tendem a desaparecer 3 anos após a separação conjugal (amato e Keith, 1991; Clarke-Stewart e tal., 2000; Hetherington, 1993). Assim, o presente estudo teve por objectivo investigar as práticas educativas de mães de famílias nucleares e monoparentais recentes (separadas há menos de três anos) e remotas (separadas há mais de três anos) e os comportamentos dos seus filhos que passaram pela transição que corresponde à entrada no ensino fundamental.

Os resultados do estudo indicam que as mães de famílias monoparentais recentes apresentam menos envolvimento com as actividades escolares e expressam menos afecto aos filhos do que as mães das famílias nucleares. Estes resultados confirmam os de outros estudos que indicam que, após a separação conjugal, as mães são mais propensas a apresentar sintomas depressivos e uma menor disponibilidade que mães de famílias nucleares (Woods et al., 2004). Isto pode ser causado pelas múltiplas exigências que ocorrem após a ruptura conjugal, tais como a necessidade de trabalhar mais tempo e negociar com o ex-cônjuge as visitas ao filho. Por sua vez, ao ficarem deprimidas e menos disponíveis, as mães podem ficar menos comunicativas, menos afectuosas com os filhos e monitorizar 
com menos frequência as tarefas escolares infantis (Martinez \& Forgatch, 2002; Pruett et al., 2003; Woods et al., 2004).

Contudo, as mães de famílias nucleares e as mães de famílias monoparentais recentes e remotas não se diferenciam quanto às práticas educativas relacionadas com as práticas disciplinares, ou seja com o estabelecimento de limites aos filhos. Estes resultados são diferentes dos encontrados na literatura, pois segundo algumas pesquisas, mães de famílias monoparentais apresentam, logo após a separação conjugal, mais práticas educativas coercitivas, permissivas e inconsistentes, o que pode prejudicar o desenvolvimento dos filhos (Forgatch \& Degarmo, 1999; Hetherington, 1993; Martinez \& Forgatch, 2002; Wolchick et al., 2000; Woods et al., 2004). Sem pôr de lado a possibilidade das mães poderem ter dado respostas que consideravam como socialmente aceitáveis, outra explicação para estes resultados seria a da limitação do instrumento que avalia estas práticas educativas parentais. Com efeito, a maioria dos seus itens investiga as práticas parentais relacionadas com o bom desenvolvimento da criança (por exemplo, expressão de sentimentos positivos, atenção, participação e monitorização de actividades de lazer e escolares da criança, etc). A única dimensão que avalia práticas menos desejáveis é a dimensão Disciplina que contempla tanto as práticas coercitivas, como as permissivas e inconsistentes. Isto pode fazer com que resultados idênticos possam corresponder a perfis disciplinares muito diferentes, o que pode explicar a ausência de diferenças nos resultados. Finalmente, outra explicação alternativa é a possibilidade de, na sociedade brasileira, a separação conjugal ter menos impacto sobre as práticas disciplinares do que sobre a manifestação de afecto ou responsabilidade, por exemplo. O que deveria ser investigado melhor em futuras pesquisas.

Além disso, os resultados sublinham que as mães de famílias nucleares, ao contrário do esperado, se diferenciam das mães de famílias monoparentais remotas em relação à maior frequência do seu envolvimento nas actividades académicas dos filhos e à demonstração de maior preocupação com o bem-estar das crianças. Contudo, as mães de famílias monoparentais separadas há menos de três anos e há mais de três anos não se diferenciam quanto às práticas parentais investigadas. Ainda que alguns autores afirmem que, imediatamente após a separação conjugal, há um desequilíbrio nas relações familiares, seguido de uma gradual estabilização das relações para a nova configuração familiar (Amato, 2000; Hetherington, 1993; Hetherington; Stanley-Hagan, 1999), pode haver uma certa persistência da disfuncionalidade familiar, além dos três anos indicados como marco pela literatura (Amato \& Cheadle, 2005; Amato \& Keith, 1991). Segundo Amato (2005), isso pode ocorrer porque algumas famílias que passam por essas transições familiares podem enfrentar, ao longo da vida, mais circunstâncias estressantes do que outras, em termos de dificuldades económicas e conflito conjugal. 
Em concordância com estudos prévios (Amato, 2005; Heterington, 1993; Lansford et al., 2006; Wood et al., 2004), os relatos das mães revelam que as crianças de famílias nucleares a presentam mais habilidades sociais associadas à cooperação e amabilidade, quando comparadas com as crianças de famílias monoparentais recentes. É interessante observar que as crianças de famílias nucleares também se diferenciam das crianças de famílias monoparentais por apresentar com mais frequência habilidades sociais que indicam controle sobre suas emoções, seja por meio de reacções abertas, tais como responder de forma socialmente aceita a provocações e pedidos abusivos, seja através de reacções encobertas como autocontrole de irritação ou raiva em situações de discussão e conflito. Pesquisas anteriores (Amato, 2005; Martinez \& Forgatch, 2002; Strohshein, 2005, Wood et al., 2004) indicam que, após a separação conjugal, as mães de famílias monoparentais tendem a apresentar menos práticas educativas consistentes, menos controle e habilidades de resolução de problemas. Com isso, as crianças, especialmente as mais novas, que necessitam de mais cuidado e monitorização, podem ser prejudicadas, uma vez que as mães poderiam, devido às dificuldades da própria transição conjugal, estar menos disponíveis para atender as necessidades da criança e ensinar-Ihe habilidades de autocontrole (Clarke-Stewart et al., 2000; Pruett et al., 2003; Ramires, 2004; Woods et al., 2004).

No que diz respeito aos problemas de comportamento, as crianças de famílias monoparentais cujas mães se separaram há menos de três anos, apresentam mais problemas de comportamento hiperactivos e externalizantes, quando comparadas às crianças de famílias nucleares. Segundo Amato (2005), as crianças de famílias nucleares são menos propensas, em relação às crianças de famílias monoparentais, a experimentar uma variedade de dificuldades cognitivas, comportamentais e emocionais, embora os estudos não demonstrem que a estrutura familiar seja responsável pelas diferenças encontradas no desenvolvimento de crianças de famílias nucleares e monoparentais (Amato, 2005). Dificuldades económicas, ausência de uma das figuras parentais (geralmente o pai), conflito conjugal e falta de práticas parentais adequadas são exemplos de eventos que podem ser estressantes para as crianças que vivem em famílias com apenas uma figura parental (Hetherington \& Stanley-Hagan, 1999). Esse tipo de estrutura familiar pode aumentar o risco de problemas comportamentais (Amato, 2000, 2005; Heterington, 1993; Lansford et al., 2006; Wood et al., 2004).

A maioria dos estudos indica que as dificuldades encontradas no desenvolvimento das crianças de famílias monoparentais são temporárias e mais exacerbadas nos primeiros anos após a separação conjugal. No entanto, contrariado a hipótese inicial, as crianças de famílias monoparentais em transição recente e remota não se diferenciam quanto às habilidades sociais de cooperação, de amabilidade e de autocontrole e quanto aos problemas de comportamento hiperactivos. $\mathrm{O}$ 
único aspecto que confirmou a hipótese inicial refere-se aos problemas de comportamento externalizantes. Isso pode indicar que as crianças de famílias que passaram pela separação conjugal podem ter em seu repertório comportamental habilidades sociais que, com o tempo, podem ser desenvolvidas com o objectivo de prevenir dificuldades sócio-emocionais e académicas (Hetherington \& StanleyHagan, 1999). Mas em relação às habilidades de autocontrole, os resultados indicam uma maior vulnerabilidade das crianças de famílias monoparentais tanto recentes quanto remotas, em relação às crianças de famílias nucleares. Woods et al. (2004) também encontraram que crianças de mães separadas há mais de três anos ainda apresentavam mais dificuldades comportamentais do que as de famílias nucleares. Porém, com o passar dos anos, as diferenças entre as crianças de famílias nucleares e monoparentais diminuíram (Woods et al, 2004). Como não há um consenso na literatura quanto à extensão, à duração e à severidade dos efeitos negativos da separação conjugal sobre o desenvolvimento infantil (Hetherington et al., 1998), é possivel que a criança necessite de mais tempo para se ajustar à nova estrutura familiar. Além disso, a transição familiar parece ter impacto diferenciado conforme as habilidades sociais da criança, que pode manifestar-se de modo recorrente. Conflitos não resolvidos durante a separação dos pais podem ressurgir mais tarde quando os filhos passam por alguma transição e precisam de enfrentar novas mudanças e tarefas desenvolvimentais (Hetherington e Stanley-Hagan, 1999).

Nesse sentido, é preciso realçar que as crianças da presente amostra enfrentam um momento sensível do seu desenvolvimento devido à transição para o primeiro ano do ensino fundamental (Trivellato-Ferreira \& Marturano, 2008). Nesse momento do desenvolvimento, as crianças precisam de mais apoio da família para ajudá-las a lidar com novas exigências académicas do contexto escolar e a desenvolver habilidades sociais necessárias à adaptação nesse ambiente. Por sua vez, o ambiente familiar tende a ficar mais instável e imprevisivel, após a separação conjugal, e dessa forma, o apoio parental às necessidades da criança pode ser prejudicado, podendo levar a dificuldades comportamentais (Amato, 2000; Hetherington \& Stanley-Hagan, 1999).

Em sintese, os resultados indicam diferenças claras entre as famílias nucleares e monoparentais recentes no que diz respeito às práticas de investimento materno na educação dos filhos e na expressão de afecto. Os filhos destes dois tipos de famílias também se diferenciam nas suas habilidades de cooperação, na amabilidade e na capacidade de autocontrole, bem como no que se refere aos problemas comportamentais hiperactivos e externalizantes. Tais resultados confirmam estudos anteriores (Amato, 2005; Martinez \& Forgatch, 2002; Pruett et al., 2003). Verificou-se ausência de diferenças quanto à expressão de afecto aos filhos entre as mães de famílias nucleares e as mães de famílias monoparentais 
remotas. As crianças de famílias nucleares e monoparentais remotas não se diferenciam também quanto às habilidades de cooperação e amabilidade, e quanto aos problemas de comportamentos externalizantes. Estes resultados parecem corroborar certos estudos anteriores que sinalizam que os efeitos negativos encontrados nas relações entre pais-filhos e no comportamento infantil, após a separação conjugal, tendem a ser temporários (Forgatch \& DeGarmo, 1999; Lansford et al., 2006; Strohschein, 2005), embora não confirmam os resultados de outros (Woods et al. (2004).

Contudo, ao contrário do que era esperado, não foram observadas diferenças entre as famílias monoparentais recentes e remotas tanto em relação às práticas parentais, como aos comportamentos e habilidades infantis, com excepção dos problemas de comportamento externalizantes. Tais resultados colocam em questão o tempo considerado suficiente ( 2 a 3 anos) para assistir ao desaparecimento total dos efeitos negativos da separação conjugal sobre pais e filhos. Se por um lado, é possível que o processo de adaptação das famílias monoparentais remotas à sua nova situação ainda não esteja totalmente concluído, pelo outro, não está fora de questão que a ausência de diferença observada entre famílias monoparentais remotas e recentes possa traduzir características específicas das famílias monoparentais, activadas quanto estas se confrontam com outras situações de vida estressantes (Amato, 2005; Amato \& Cheadle, 2005). Para verificar essas hipóteses seria necessário poder comparar famílias monoparentais remotas com tempos de separação conjugal diferentes.

\section{Conclusões}

Os resultados confirmam o impacto da separação conjugal sobre as dificuldades comportamentais observadas nas crianças, o que sublinha a importância de se considerarem as práticas educativas parentais, o tempo da separação conjugal e o momento do desenvolvimento infantil quando se procura investigar o impacto das transições familiares. Uma importante contribuição do estudo foi não apenas avaliar as dificuldades comportamentais das crianças, mas também investigar as suas habilidades sociais e as práticas educativas parentais que estão classicamente relacionadas com o bom desenvolvimento infantil. Como as habilidades sociais podem funcionar como factores de protecção, a sua diminuição, mesmo que temporária, pode tornar a criança mais vulnerável e com mais dificuldade de lidar com as exigências de outras transições, tal como a entrada no primeiro ano. Esta dupla exigência, nesta faixa etária, tem sido pouco explorada nos estudos sobre transições familiares (Clarke-Stewrat et al., 2000). 
A separação conjugal deve ser considerada como um processo complexo que envolve tanto habilidades individuais quanto aspectos económicos e sócioculturais no ajustamento dos membros da família à esta transição (Cherlin, 2005; Hetherington \& Stanley-Hagan, 1999). Muitas pesquisas porém baseiam-se num modelo de déficit, isto é, focam as práticas parentais ineficientes e os problemas de comportamento das crianças de famílias monoparentais, dificultando a identificação de recursos individuais que podem funcionar como factores de protecção a ser desenvolvidos em intervenções psicológicas (Hetherington et al., 1998). Neste caso, os resultados do estudo chamam a atenção para a importância das habilidades sociais infantis das crianças de famílias monoparentais que ficaram enfraquecidas. Ressalta-se que para situar as dificuldades que ocorrem nas famílias que passam pela separação conjugal, é preciso considerar que, ainda que este evento esteja associado com mudanças estressantes para a vida dos seus membros, pode ser uma oportunidade para pôr termo ao conflito conjugal, para mais previsibilidade e estabilidade no ambiente familiar (Hetherington \& Stanley-Hagan, 1999). Assim, a intervenção psicológica com as mães que ficaram com a guarda da criança poderà tornar este acontecimento de vida promotor do desenvolvimento adulto.

Contudo, o delineamento transversal deste estudo constitui uma limitação. A utilização de metodologias de natureza longitudinal poderia ser útil para poder avaliar como as práticas parentais se alteram com o passar do tempo e como as crianças se comportam em consequência. Seria interessante estudar um leque mais amplo de famílias monoparentais recentes e remotas, fazendo variar o tempo além dos 3 anos, pois os factores de risco e de protecção não são estáticos e mudam durante muito tempo após a separação conjugal.

\section{Referências bibliográficas}

ABPE, (2008). Associação Brasileira de Empresa de Pesquisa. Dados com base no levantamento socioeconômico 2006 e 2008 - IBOPE, Online: http://www.abpe.org <acessado em O2 de fevereiro de 2010>.

Ackerman, B. P., Kogos, J., Youngstrom, E., Shoff, C., \& Izard, C. (1999). Family instability and the problem behavior of children from economically disadvantaged families. Developmental Psychology, 35 (1), 258-268.

Alvarenga, P., \& Piccinini, C. (2001). Práticas educativas maternas e problemas de comportamento em pré-escolares. Psicologia: Reflexão e Crítica, 14 (3), 449-460.

Amato, P. R. (2000). The consequences of divorce for adults and children. Journal of Marriage and the Family, 62 (4), 1269-1287.

Amato, P. R. (2005). The impact of family formation change on the cognitive, social, and emotional well-being of the next generation. The Future of Children, 15 (2), 75-96. 
Amato, P. R., \& Cheadle, J. (2005). The long reach of divorce: tracking marital dissolution and child well-being across three generations. Journal of Marriage and Family, 67, 191-206.

Amato, P. R., \& Keith, B. (1991). Parental divorce and the well-being of children: a metaanalysis. Psychological Bulletin, 11 (1), 26-46.

Bandeira, M., Del Prette, Z. A. P., Del Prette, A., \& Magalhães, T. (2009). Validação das Escalas de Habilidades Sociais, Comportamentos Problemáticos e Competência Acadêmica (SSRS-BR) para o ensino fundamental. Psicologia: Teoria e Pesquisa, 25 (2), 271-282.

Benetti, S. P. da C., \& Balbinotti, M. A. (2003). A Elaboração e estudo de propriedades psicométricas do Inventário de Práticas Parentais. Psico-USF, 8 (2), 103-113.

Baumrind, D. (1971). Current patterns of parental authority. Developmental Psychology Monograph, 4, 1-103.

Clarke-Stewart, K. A., McCartney, K., Booth, C., Vandell, D. L., \& Owen, M. T. (2000). Effects of parental separation and divorce on very young children. Journal of Family Psychology, 4, 304-326.

Costa, C. S. L., Cia, F., \& Barham, E. J. (2007). Envolvimento materno e desempenho acadêmico: comparando crianças residindo com as mães e com ambos os pais. Revista Brasileira de Psicologia Escolar e Educacional, 11 (2), 339-351.

Dishion, T. J., \& McMahon, R. J. (1998). Parental monitoring and the prevention of child and adolescent problem behavior: a conceptual and empirical formulation. Clinical Child and Family Psychology Review, 1, 61-75.

Forgatch, M. S., \& DeGarmo, D. S. (1999). Parenting through change: an effective prevention program for single mothers. Journal of Consulting and Clinical Psychology, 67 (5), $711-724$.

Gomide, P. I. C. (2003). Estilos parentais e comportamento anti-social. In: A. Del Prette \& Z. A. P. Del Prette (Orgs.). Habilidades Sociais, Desenvolvimento e Aprendizagem: questões conceituais, avaliação e intervenção. (pp. 21-61). Campinas: Editora Alínea.

Greshan, F., \& Elliott, S. (1990). Social Skills System: manual. Circle Pines, MN: American Guidance Service.

Grzybowsky, L. S. (2007). Parentalidade em tempo de mudanças: desvelando o envolvimento parental após o fim do casamento. Tese (Doutorado). Pontifícia Universidade Católica do Rio Grande do Sul, Rio Grande do sul, RS.

Hetherington, E. M. (1993). An overview of the Virginia longitudinal study of divorce and remarriage with a focus on early adolescence. Journal of Family Psychology, 2 (1), 39-56.

Hetherington, E. M., Bridges, M., \& Glendessa, M. I. (1998). What matters? What does not? Five perspectives on the association between marital transitions and children's adjustment. American Psychologist, 53 (2), 167-184.

Hetherington, E. M., \& Stanley-Hagan, M. (1999). The adjustment of children with divorced parents: a risk and resiliency perspective. Journal of Child Psychology and Psychiatry, 40 (1), 129-140.

Hoffman, M. L. (1979). Development of moral thought, feeling and behavior. American Psychologist, 34, 959-966.

Johnson, V. K., Cowan, P. A., \& Cowan, C. P. (1999). Children's classroom behavior: the unique contribution of family organization. Journal of Family Psychology, 13, (3), 355-371.

Kelly, J. B., \& Emery, R. E. (2003). Children adjustment flowing divorce: risk and resilience perspective. Family Relations, 52 (4), 352-362. 
Kilgore, K., Snyder, J., \& Lentz, C. (2000). The contribution of parental discipline, parental monitoring, and school risk to early-onset conduct problems in African American boys and girls. Developmental Psychology, 36 (6), 835-845.

Lansford, J. E. (2009). Parental divorce and children's adjustment. Perspectives on Psychological Science, 4 (2), 140-152.

Lansford, J. E., Malone, P. S., Castellino, D. R., Dodge, K. A., Bates, J. E., \& Petit, G. S. (2006). Trajectories of internalizing, externalizing, and grades for children who have and have not experienced their parents' divorce. Journal of Family Psychology, 20, 292-301.

Leon K. (2003). Risk and protective factors in young children adjustment to parental divorce: a review of the research. Family Relations, 52 (3), p. 258-270.

Martinez, C. R. J., \& Forgath, M. S. (2002). Adjusting to change: linking family structure transitions with parenting boys' adjustment. Journal of Family Psychology, 16 (2), 107-117.

Maroco, J. (2007). Análise estatística com a utilização do SPSS. 3 ed. Lisboa: Edições Síbalo.

Page, T., \& Bretherton, I. (2003). Gender differences in stories of violence and caring by preschool children in post-divorce families: implications for social competence. Child and Adolescence Social Work Journal, 20 (6), 485-508.

Pruett, M. K., Williams, T. Y., Glendessa, I., \& Little, T. D. (2003). Family and legal indicators of child adjustment to divorce among families with young children. Journal of Family Psychology, 17 (2), 169-180.

Ramires, V. R. R. (2004). As transições familiares: a perspectiva de crianças e pré-adolescentes Psicologia em Estudo, 9 (2), 183-193.

Strohschein, L. (2005). Parental divorce and child mental health trajectories. Journal of Marriage and Family, 67, 1286-1300.

Trivellato-Ferreira, M., \& Marturano, E. M. (2008). Recursos da criança, da família e da escola predizem competência na transição da $1^{\text {a }}$ série. Revista Interamericana de Psicología, 42 (2), 549-558.

Wagner, A. (2002). Familia em cena: tramas, dramas e transformações. Petrópolis, RJ: Vozes.

Wood, J. J., Repetti, R. L., \& Roesch, S. C. (2004). Divorce and children's adjustment problems at home and school: the role of depressive/withdrawn parenting. Child Psychiatry and Human Development, 35 (2), 121-142.

Wolchik, S. A., Wilcox, K. L., Tein, J. Y., \& Sandler, I. N. (2000). Maternal acceptance and consistency of discipline as buffers of divorce stressors on children's psychological adjustment problems. Journal of Abnormal Child Psychology, 28 (1), 87-102.

\section{Marital separation and its relationship to parental practices and child behavior}

This study investigates the parenting practices of mothers in nuclear and single parent families, as well as their children's behavior in the transition of first grade of elementary school. Participants are 33 nuclear family mothers, 33 single mothers who have been separated for less than three years and 33 single mothers who have been separated for over three years. The instruments used are: a Brazilian measure of socioeconomic status; Parental Practices Inventory; Social Skills Rating 
System. The last two instruments are found to have good psychometric properties. The ANOVAS indicated that mothers in nuclear families invest more in educating their children and demonstrate more affection to children than recently separated single mothers. However, mothers from different family configurations do not differ regarding the disciplinary practices. The children of nuclear families are more socially skilled and have fewer behavior problems than children from single parent families. It is argued that parenting practices, the time of divorce and the timing of development are important variables that must be considered when investigating the impact of family transitions on children's development.

KEY-WORDS: Marital separation; Parental practices; Child behavior.

\section{Séparation conjugale et sa relation avec les pratiques parentales et le comportement de l'enfant}

Cette étude examine les pratiques parentales des mères de familles nucléaires et monoparentales et le comportement de leurs enfants lors de la transition que constitue la première année de l'école élémentaire. Ont participé à cette étude 33 mères de familles nucléaires, 33 mères séparées de leur conjoint depuis moins de trois ans et 33 mères séparées depuis plus de trois ans. Les instruments utilisés sont les suivants: un questionnaire pour évaluer le statut socioéconomique; l'Inventaire de Pratiques Parentales; le Système d'Évaluation des Compétences Sociales. Les propriétés psychométriques des deux derniers instruments sont satisfaisantes. Les résultats de l'ANOVA montrent que les mères des familles nucléaires investissent davantage dans l'éducation de leurs enfants; elles démontrent aussi plus d'affection pour les enfants que les mères de familles monoparentales récemment séparées. Toutefois, les mères de différentes configurations familiales ne diffèrent pas en ce qui concerne les pratiques disciplinaires. Les enfants des familles nucléaires sont plus compétents socialement et ont moins de problèmes de comportement que les enfants de familles monoparentales. Au cours de la discussion, on souligne l'importance des pratiques parentales, du moment du divorce et de la phase de développement en tant que variables qui doivent être considérées lors d'études portant sur l'incidence des changements familiaux sur le développement des enfants.

MOTS-CLÉS: Divorce, Pratiques parentales, Comportement des enfants. 